\title{
¿DISCUSIÓN ENTRE EL DERECHO \\ NATURAL Y EL POSITIVISMO JURÍDICO?
}

Martín D. Farrell

Universidad de Buenos Aires (Argentina)

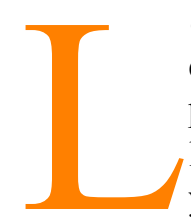

o único que me propongo mostrar aquí es mi perplejidad por la persistencia con que en la filosofía del derecho se continúa discutiendo un tema cuya importancia para la polémica se me escapa por completo. En efecto: en el centro mismo de la filosofía del derecho aparece inexorablemente la polémica entre iusnaturalistas y positivistas acerca del concepto de derecho. La discusión se presenta por lo general en estos términos: el partidario del derecho natural requiere de conceptos morales para caracterizar al derecho, mientras que el partidario del positivismo jurídico sostiene que puede prescindir de tales conceptos para realizar esa misma tarea.

Así enunciada, la discusión parece ser, en realidad, muy importante, pues su tema central sería, nada menos, que la relación entre la moral y el derecho; el tema discutido -aparentemente- es el de si la moral cumple o no un papel dentro del derecho. Sin embargo, me parece que esta es una versión exagerada del problema: la verdadera discusión es mucho menos dramática y, por supuesto, mucho menos importante.

En lo que sigue, voy a presentar primero la versión usual de la polémica, para mostrar luego lo que yo considero su versión real. Para ello, debo tomar como ejemplos a un modelo de la teoría del derecho natural y a un modelo del positivismo jurídico que abarquen las distintas variantes de esas teorías. Espero poder hacerlo sin deformar las teorías reales, y que las versiones que presente -aunque no sean tal vez sostenidas estrictamente en esa forma por ningún autor- tampoco sean caricaturas de las teorías originales. Mostrar, luego, el alcance y papel que tienen los distintos criterios identificatorios del derecho, para restarle también importancia a la polémica entre positivistas jurídicos y realistas del derecho, y concluir, proponiendo un tema de discusión que considero más importante que el presente, aunque -como veremos- no parece ser estrictamente un tema de la filosofía del derecho. 


\section{La versión dramática}

Entender, por la teoría del derecho natural a aquélla que sostiene que no puede identificarse a algo como derecho -que no puede, en otras palabras, identificarse a una norma como jurídica- sin recurrir a conceptos morales. El contenido del derecho tiene que ajustarse al contenido de la moral. Si la norma es inmoral no es jurídica: no existe el derecho injusto, puesto que tal expresión es contradictoria.

La teoría puede inclinarse también, desde luego, por una versión más débil; puede aceptar que un sistema jurídico contenga alguna norma inmoral, pero que el sistema mismo -en general- debe ajustarse a los preceptos de la moral.

Entender -a su vez- por la teoría del positivismo jurídico a aquélla que sostiene que puede identificarse a algo como derecho -que puede identificarse a una norma como jurídica- sin necesidad de recurrir a conceptos morales; el contenido del derecho no tiene por qué ajustarse -en ningún grado- al contenido de la moral. Una norma jurídica puede ser inmoral: existe el derecho injusto, y la expresión no es para nada contradictoria.

También esta teoría puede inclinarse por una versión más débil, y aceptar que el derecho requiere un mínimo ajuste con la moral, por una simple cuestión de eficacia. Pero no es necesario -en general- que el sistema jurídico se ajuste a los preceptos de la moral de acuerdo al criterio positivista.

Lo primero que se advierte en la caracterización del positivismo jurídico que he presentado, desde luego, es que ella es excesivamente amplia: de acuerdo con esta versión, en efecto, todos los realistas jurídicos serían -a la vez- positivistas jurídicos. No me importa esta consecuencia de mi caracterización (que de alguna manera no es errónea); lo que quiero mostrar no es sólo que la polémica entre los partidarios del derecho natural y del positivismo jurídico no tiene la importancia que se le suele asignar, sino que tampoco es importante que el derecho natural polemice con los realistas. De modo que prefiero resaltar el rasgo común que une a positivistas y realistas (caracterizar al rasgo genérico de las teorías que se oponen al derecho natural) antes que mostrar sus diferencias específicas, que son irrelevantes para mi propósito.

Si la discusión se presenta de esta manera, la polémica parece dramática; en un caso la moral tiene relación con el derecho, mientras que en el otro son dos sistemas normativos totalmente separados. De aquí suele seguirse otra consecuencia igualmente dramática: si se acepta la versión positivista, no hay manera de evaluar moralmente al derecho. Da lo mismo el derecho justo que el injusto, el correcto que el incorrecto, el bueno que el malo; más 
aún: también se seguiría que es obligatorio obedecer a cualquier derecho, no importando su grado de inmoralidad.

Es claro que si la discusión tiene estos alcances ella es realmente importante y se explica que haya acaparado tanta atención por parte de los filósofos del derecho durante tanto tiempo. Pero creo, justamente, que la versión que acabo de describir exagera notablemente el ámbito de la polémica.

\section{La versión desdramatizada}

¿Qué es lo que falla en la descripción anterior? La caracterización del positivismo jurídico, por supuesto; pero no porque la teoría positivista se confunda con la de los realistas sino porque la versión que he proporcionado permite confundir a un positivista jurídico con un positivista ideológico. El positivista ideológico sostiene, a la vez, dos cosas: a) que no es necesario que el sistema jurídico se ajuste a los preceptos de la moral para merecer el nombre de derecho, $y b$ ) que es obligatorio obedecer al derecho.

Ahora bien: en un sentido trivial, todos coincidimos en que es obligatorio obedecer al derecho, y este es el sentido que reconoce que si alguien desobedece una norma jurídica es muy probable que sufra una sanción como consecuencia. En la medida en que existe una conducta exigida por una norma jurídica, la violación de la norma implica un castigo, por lo que es obligatorio en este sentido obedecer al derecho si se quiere evitar la sanción. Pero el positivista ideológico está diciendo algo más: está diciendo que este es el único sentido de obligación, que toda otra evaluación del derecho para establecer su carácter obligatorio -la evaluación moral, por ejemplo- es irrelevante.

No sé si algún autor ha sostenido alguna vez la tesis del positivismo ideológico; lo que sí puedo decir es que el positivismo ideológico es una caricatura del positivismo jurídico.

Este último sostiene también dos cosas, pero no las dos con el alcance que les asigna el positivismo ideológico. El positivista jurídico sostiene, incondicionalmente, a) que no es necesario que el sistema jurídico se ajuste a los preceptos de la moral para merecer el nombre de derecho, y, condicionalmente, b) que es obligatorio obedecer al derecho. Condicionalmente en la medida en que acepta que si una norma jurídica no es obedecida se seguirá probablemente una sanción como consecuencia; pero no, por cierto, en el sentido de afirmar que éste es el único sentido inteligible de obligación y que la evaluación moral del derecho es irrelevante.

El positivista jurídico evalúa moralmente al derecho, a efectos de determinar su obligatoriedad, tanto como lo hace el partidario del derecho natural. La única diferencia entre ambos es el momento en que esa evaluación se lleva a cabo. 
El partidario del derecho natural realiza esa evaluación al comienzo de su trabajo; antes de permitir que una norma sea considerada derecho, el iusnaturalista la somete a un escrutinio moral: si la norma no se ajusta a los dictados de la moral, la norma no es jurídica. (Como he dicho, hay versiones más permisivas, que evalúan al sistema como un todo y no norma por norma).

El positivista jurídico realiza esa misma evaluación al final de su trabajo; luego de aplicar su test preferido para determinar si algo es derecho, test que varía de autor en autor, pero que siempre tiene en común que prescinde de la moral, el positivista evalúa moralmente el derecho. Necesita hacerlo porque le interesa saber, entre otras cosas, si el derecho es justo o injusto. Y hay algo que le interesa especialmente, puesto que no es un positivista ideológico: le interesa saber si existe una obligación de obedecer al derecho.

Esa obligación tiene un sentido más profundo que aquel al que me he referido antes: el positivista está pensando ahora si es moralmente obligatorio obedecer al derecho. Y bien puede concluir que no es moralmente obligatorio obedecer a un determinado sistema jurídico, y hasta puede concluir en que el sistema es tan inmoral que es moralmente obligatorio desobedecerlo. (Hay una diferencia entre no obedecer y desobedecer, como lo muestra el siguiente ejemplo: Supongamos que nuestro positivista vive en la antigua Sudáfrica del apartheid, donde existe una norma jurídica que castiga a todo blanco que se bañe en una playa de negros, y viceversa. El positivista en cuestión, que es blanco, evalúa moralmente al derecho y, después de considerarlo inmoral, puede hacer dos cosas: a) no obedecerlo, esto es, no bañarse en una playa destinada sólo a los blancos, o, b) desobedecerlo, esto es, bañarse en una playa destinada sólo a los negros).

De manera que tanto el iusnaturalista como el positivista evalúan moralmente al derecho; la única diferencia entre ambos reside en el momento en que ellos llevan a cabo esa evaluación. Y las consecuencias prácticas de ambas evaluaciones son las mismas: mientras el iusnaturalista llega a la conclusión de que no hay que obedecer a las normas inmorales porque no son derecho, el positivista llega a la conclusión de que no hay que obedecerlas, pese a que son derecho, porque son inmorales.

\section{Las ventajas del positivismo}

La versión desdramatizada muestra que la discusión entre el derecho natural y el positivismo jurídico ha perdido su importancia: no se trata de una discusión acerca de si la moral tiene alguna relación con el derecho, sino de una discusión acerca de cuándo debe estudiarse la relación entre la moral y 
el derecho, relación que ninguno de los contendientes niega. Y las consecuencias de estudiar esa relación en un momento o en el otro son las mismas.

Parecería, entonces, que es indiferente elegir el test del derecho natural o el test positivista para determinar si una norma es o no jurídica (o si un sistema lo es o no). No obstante, yo creo que el test positivista presenta una ventaja frente a su rival, ventaja que ahora que la discusión se ha desdramatizado los iusnaturalistas no deberían tener inconveniente en reconocer; la ventaja consiste en que el test positivista tiene un rango explicativo mayor.

En efecto: supongamos que la tarea que se presenta ante nosotros consiste en describir un sistema normativo respecto del cual existe una coincidencia entre el filósofo positivista y el filósofo iusnaturalista en el sentido de que el sistema en cuestión es inmoral; estoy pensando, por ejemplo, en el régimen de la Alemania nazi, en el de la Unión Soviética stalinista y en el de la Sudáfrica del apartheid. Mientras el positivista no tiene ningún inconveniente en describir a esos sistemas como derecho, el iusnaturalista no puede hacerlo, por cuanto se trata de sistemas normativos que él (al igual que el positivista) considera inmorales.

Ahora bien: el iusnaturalista puede decirnos que cualquiera de esos sistemas no es derecho, pero es muy claro que esa afirmación es insuficiente para nuestros propósitos; nosotros queremos saber qué son esos sistemas, no que no son. Si yo enfrento a un zoólogo con un animal determinado, y le pregunto qué es, no me quedaría conforme si el zoólogo en cuestión me respondiera que el animal en cuestión no es un cisne; la respuesta es insuficiente para mis fines.

Sin embargo, me temo que ésa es toda la respuesta que el iusnaturalista puede dar. El sistema normativo nazi no es moral, como ya vimos, no es tampoco religioso, ni está compuesto por normas de cortesía; no es tampoco un sistema compuesto de órdenes emitidas por bandoleros, porque en la Alemania nazi también había bandoleros, en el sentido estricto del término, que a veces eran apresados, y resultaban condenados por los jueces nazis, en base al código penal nazi.

Me parece que no hay más remedio que reconocer que el sistema nazi era derecho. ¿Cuál es el motivo de la resistencia del iusnaturalista a admitir esta circunstancia? Supongo que las derivaciones que se seguían de la versión dramática expuesta al comienzo; sin embargo, no creo que esa resistencia se justifique si se adhiere a la versión desdramatizada.

En esta última, designar a algo como derecho no implica reconocer que es justo, bueno, correcto o moral, y -más importante aún- no implica que es obligatorio, en el sentido relevante del término que he examinado antes. Pero yo estoy incurriendo ahora en el mismo defecto que le imputaba hace un instante al iusnaturalista respecto de su versión del nazismo: estoy di- 
ciendo lo que reconocer a algo como derecho no es, sin explicar en cambio lo que es. Voy a ello.

La conducta de los individuos está regulada por distintos tipos de normas, y es adecuado distinguir cuatro de esos tipos, como hice hace un momento (sin pretender que la distinción sea exhaustiva): a) normas de cortesía; b) normas morales; c) normas religiosas, y d) normas jurídicas. ¿Qué tarea cumplen los tests que identifican a cada uno de esos tipos de normas?

Los tests predicen las consecuencias que se siguen de la desobediencia a esas normas. Por ejemplo: si un test identifica a una norma como norma de cortesía, lo que está haciendo es una predicción; está prediciendo lo que me va a ocurrir (a mí o a cualquier otro) si desobedezco la norma; la predicción diría que en ese caso voy a ser mirado de mala manera, que tal vez voy a ser objeto de algún reproche verbal... y nada más. Si el test es adecuado, esas serán realmente las consecuencias que el desobediente va a padecer.

Identificar a una norma como moral es predecir que si la desobedezco padeceré, un reproche, ahora algo mayor que en el caso del quebrantamiento de una norma de cortesía, que probablemente sufriré, también alguna reacción verbal y que varias personas evitarán mi presencia. Si el test es adecuado, esas serán realmente las consecuencias que el desobediente va a padecer.

Identificar a una norma como religiosa es predecir que si la desobedezco cometeré, un pecado (en el caso de ciertas religiones) y me haré acreedor de un castigo en el otro mundo (y, bajo ciertos regímenes, también en éste, aunque en este caso la norma religiosa tiende a confundirse con la jurídica). Es difícil verificar en este mundo, por cierto, la adecuación de este test.

Por último, identificar a una norma como jurídica es predecir que si la desobedezco sufriré, probablemente una sanción, prevista en esa norma o en otras normas semejantes a ella, aplicada por un determinado órgano, también previsto en esa norma u otra semejante, y que consiste en la privación coactiva de un bien, tal como la vida, la salud, la libertad, o la propiedad, al par de verse también afectado mi honor. Si el test es adecuado, esas serán realmente las consecuencias que el desobediente va a padecer.

Pero si esto es todo lo que se propone hacer el test de identificación de normas jurídicas (y de acuerdo a la versión desdramatizada esto es todo lo que se propone hacer), ¿cómo puede continuar la discusión acerca de cuál es el mejor test? El mejor test -obviamente- es el que mejor predice las consecuencias de mi acción. Supongamos que yo quiero saber qué tipo de norma es la que ordena el uso de corbata; un buen test me diría que si soy un civil, en la mayoría de los casos se trata de una norma de cortesía, cuya desobediencia sólo me acarreará un tibio reproche, pero también tiene que informarme que si soy un militar, en determinados casos es una norma jurí- 
dica, cuya desobediencia me acarreará ciertas sanciones aplicadas por el órgano militar.

Si ésta es la tarea del test, la discusión acerca de la bondad del mismo es superflua; de un modo empírico podemos comprobar con facilidad cuál de los tests propuestos es el mejor. Aquí «el mejor» quiere decir -sencillamente- aquél que mejor predice las consecuencias que se siguen de no obedecer la norma: el que tiene un mayor porcentaje de ajuste con la realidad.

El tema de la obediencia al derecho, como se ve, no está en juego en este caso. No sólo no se sigue de identificar a algo como derecho que hay una obligación moral de obedecerlo, sino que ni siquiera se sigue que la obediencia al derecho sirve siempre como excusa jurídica. Los jerarcas nazis aprendieron esta verdad a su costa en los juicios de Nüremberg, donde invocaron sin éxito la obediencia a las normas jurídicas nazis para evitar la sanción que les correspondía de acuerdo al nuevo orden jurídico que se les aplicaba. Y en la Argentina se hubiera producido una situación similar de no mediar la ley de obediencia debida; la sola circunstancia de que haya sido jurídicamente necesario dictar una ley especial de obediencia debida es prueba de la verdad de lo que afirmo.

En suma: la discusión entre el derecho natural y el positivismo jurídico sólo se explica en la versión dramatizada del tema. En la versión desdramatizada, que yo sostengo que es la versión completa del tema, la discusión pierde su importancia, y también pierde importancia la discusión entre positivistas jurídicos y realistas (sean ellos norteamericanos o escandinavos). Todos ellos comparten la idea de que puede identificarse a una norma como jurídica sin recurrir a conceptos morales. ¿Qué les queda entonces por discutir? También aquí debo recordar que el acuerdo entre positivistas y realistas es más fácil de lo que se lo ha hecho parecer: ambos buscan las consecuencias que se siguen de desobedecer una norma jurídica sin recurrir para ello a la moral. Se suele minimizar -no obstante- las coincidencias de ambas posiciones y exagerar -en cambio- la importancia de una diferencia: el plano en el cual se encuentra la consecuencia de desobedecer a la norma jurídica (el normativo para el positivista y el empírico para el realista).

No estoy sugiriendo, sin embargo, que yo pienso que se han agotado los temas dignos de discusión, y quiero concluir mostrando uno que sí considero de importancia.

\section{Algo para discutir}

Lo que no es importante, como acabo de mostrar, es el momento en que debe efectuarse la evaluación moral del derecho; con los alcances que le he asignado, el mejor test identifica primero al derecho sin apelar a conceptos morales, para evaluar moralmente de inmediato el material así identificado. 
Pero si no es importante cuándo se efectúa la evaluación moral, sí lo es qué tipo de evaluación se practica. Supongamos que dos personas que comparten la misma teoría moral discrepan acerca del momento de la evaluación; no deberían discutir sobre este tema, a mi juicio, porque, un momento antes o un momento después, ellos habrán alcanzado una completa coincidencia sobre el asunto.

Sin embargo, supongamos ahora que dos personas coinciden acerca de cuándo hay que practicar la evaluación moral del derecho, pero discrepan respecto de la teoría moral que debe aplicarse para ello; uno es un utilitarista, por ejemplo, y el otro es un deontologista kantiano. En este caso la coincidencia acerca del cuando no les sirve de nada, porque difícilmente puedan ponerse de acuerdo acerca del tema central de su diferencia, esto es, acerca de si es moralmente obligatorio obedecer a ese sistema normativo.

Lo que hay que discutir, entonces, no es cuándo se evalúa moralmente al derecho, sino cuál es la mejor teoría moral con la cual el derecho debe compararse; pero éste -supongo- es un tópico de la ética, y no de la filosofía del derecho. De donde -tal vez- pueda concluir mostrando un dilema: el tema aparentemente más importante de discusión en la filosofía del derecho no tiene la importancia que se le asigna, y el tema realmente importante no es un tema de la filosofía de derecho. 